\title{
Case report: The management of advanced oral cancer in a Jehovah's Witness using the Ultracision Harmonic Scalpel
}

\author{
Peter J Kullar ${ }^{1 *}$, Kristian Sorenson², Ruwan Weerakkody ${ }^{1}$ and James Adams ${ }^{1}$
}

\begin{abstract}
We present the first case of a head and neck oncological procedure accomplished in a Jehovah's Witness using the Ultracision Harmonic Scalpel (Ethicon, Cincinnati, OH). Jehovah's Witnesses present a serious challenge to the head and neck cancer surgeon due to their refusal to accept transfusion of any blood products. However, our experience reinforces the view that surgical management of head and neck cancer is possible in these patients. We show the Harmonic Scalpel, an ultrasonic tissue dissector, to be a useful surgical tool in obviating the need for blood transfusion. Preoperative optimisation, intra-operative surgical and anaesthetic techniques are also fully discussed.
\end{abstract}

Keywords: Harmonic scalpel, Head and neck cancer, Jehovah's Witness

\section{Background}

Jehovah's Witnesses (JW) are a substantial Christian denomination, numbering up to 7 million with a presence in almost all countries worldwide. They are governed by a group of elders exercising authority on all doctrinal matters based on their own translation of the bible. Of particular relevance to medical practice is their refusal, since 1945, to accept blood transfusions even in cases of medical emergency [1] This has been the centre of a number of high profile medical ethics cases [2]. The Harmonic Scalpel (HS), an ultrasonic dissector coagulator (Figure 1; Ethicon, Cincinnati, $\mathrm{OH}$ ), is a new surgical tool which simultaneous cuts and coagulates tissues. Here we report a case of a large oral cancer and neck dissection with free flap reconstruction performed in a JW with the HS obviating the need for blood products.

\section{Case presentation}

A 48 year old female Caucasian JW presented with nonhealing ulcerated lower right second and third molar extraction sockets in 2005. Her past medical history was

\footnotetext{
* Correspondence: peterkullar@hotmail.com

'Department of Maxillofacial Surgery Royal Victoria Hospital Newcastle-UponTyne UK

Full list of author information is available at the end of the article
}

unremarkable. She was a non-smoker and consumed only moderate amounts of alcohol in accordance with her religious beliefs. Biopsy was performed confirming a moderately differentiated squamous cell carcinoma (SCC), staged by whole body computed tomography (CT) as T4N0M0. She was initially treated with primary chemoradiotherapy as blood products were deemed to be essential for surgical resection at this time. She received 63 Grays of radiation and 5 cycles of cisplatin. Post-treatment she was deemed to be tumor free.

In 2006 she presented with an unstable ulcer on the left lateral tongue. Biopsy revealed early invasive pT1 SCC. This was treated with laser excision.

She was followed up at monthly intervals, however, in 2009 she presented with a lower right retromolar mass eroding into the mandible (Figure 2, Panorex image). Biopsy revealed Human Papiloma Virus (HPV) negative SCC staged at CT as T4NOM0. Treatment plans were devised after extensive discussion at the Head and Neck Cancer Multi-Disciplinary Team (MDT) meeting. This case was particularly complex given the previous chemoradiotherapy and the inability to use blood products in the case of severe blood loss. Salvage surgery was deemed most appropriate with the proviso that new surgical techniques could now minimize blood loss.
C Biomed Central

(ㄷ) 2011 Kullar et al; licensee BioMed Central Ltd. This is an Open Access article distributed under the terms of the Creative Commons Attribution License (http://creativecommons.org/licenses/by/2.0), which permits unrestricted use, distribution, and reproduction in any medium, provided the original work is properly cited. 


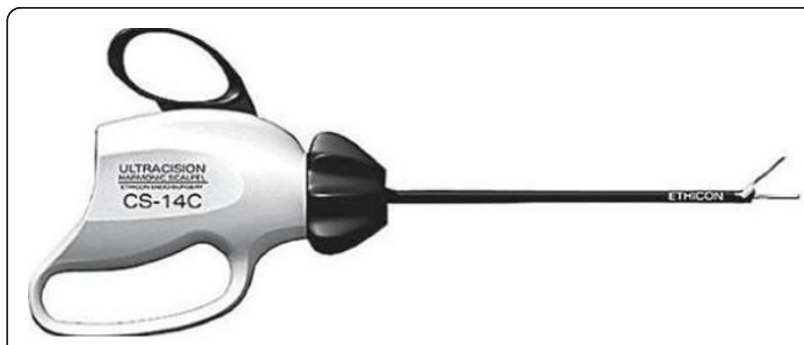

Figure 1 Ultracision Harmonic Scalpel (Ethicon, Cincinnati, $\mathrm{OH}$ ). http://www.ethiconendosurgery.com/Clinician/Product/energy/.

As the patient was unwilling to accept any blood products all efforts were directed at preoperatively optimisation and minimization of intra-operative blood loss. Preoperative blood tests showed haemoglobin $(\mathrm{Hb})$ of $11 \mathrm{~g} / \mathrm{dl}$, platelets $310 \times 10^{9} / \mathrm{l}$ and a normal clotting profile. She was assessed by a haematologist who prescribed a 2 week preoperative course of oral ferrous sulphate. No further preoperative treatment was instigated.

At operation the patient was premedicated with a statim dose of 1 gram tranexamic acid and anaestethseia was induced with a combination of propofol $(120$ $\mathrm{mg})$, fentanyl (100 $\mathrm{mcg}$ ) and vecuronium $(8 \mathrm{mg})$. Anaesthesia was maintained using a remifentanil infusion $(50 \mathrm{mcg} / \mathrm{ml}$ at $10 \mathrm{ml} / \mathrm{hr}$ ) and sevofluorane gas inhalation. Hypervolameic hemodilution was performed using preloading with $15 \mathrm{ml} / \mathrm{kg}$ cryastalloid fluid in conjunction with the controlled hypotension using remifentanil infusion maintaining a mean arterial pressure of $65 \mathrm{mmHg}$. The patient was placed in a head up position and meticulous attention to blood loss was performed throughout the whole operation. Blood loss was charted continuously during the operation. Intraoperative blood sampling also provided a guide to blood loss and the $\mathrm{Hb}$ did not drop below $9.6 \mathrm{~g} / \mathrm{dl}$ during the operation. The intraoperative clotting profile revealed a normal prothrombin (PT) and activated partial throboplastin time (APTT).

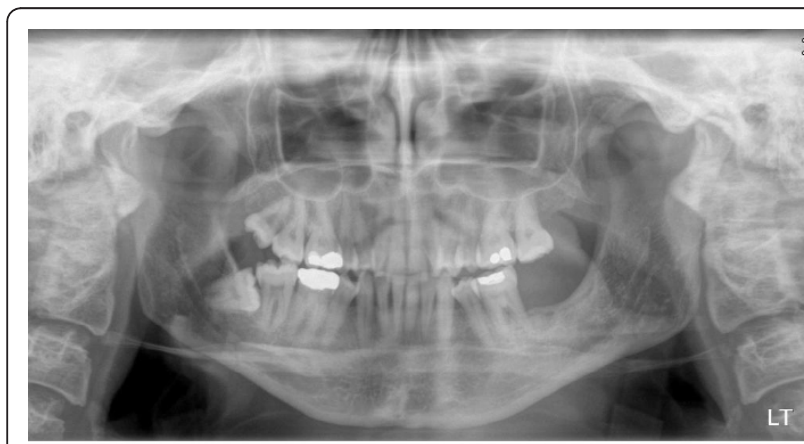

Figure 2 Panorex image demonstrating lower right retromolar mass eroding into the mandible (2009).
A left tonsillar and retromolar with mandibular rim resection was undertaken and reconstructed with a radial forearm free flap (Figure 3, resection specimen). A left level I-IV neck dissection and covering tracheostomy was also performed (Figure 4, neck dissection). The surgeon (JA) used the HS throughout the procedure. The radial forearm flap was raised by the Plastics Surgical team (KS) using a standard technique with cold steel dissection.

The entire procedure was accomplished in approximately 11 hours. The total blood loss was under $500 \mathrm{ml}$. During the operation Hartmann's solution was infused at $100 \mathrm{ml} / \mathrm{hr}$ (Total $1.1 \mathrm{~L}$ ). The urine output was $500 \mathrm{ml}$ giving an intra-operative fluid balance of $+0.1 \mathrm{~L}$.

The patient was transferred to the intensive care unit for close monitoring on the first postoperative night. She was then returned to the specialised otolaryngology ward. The patient had a single episode of self resolving supraventricular tachycardia but the rest of the postoperative course was uneventful. She was discharged home able to eat a soft diet and with good speech function 2 weeks postoperatively. Her postoperative haemoglobin did not drop below $10 \mathrm{~g} / \mathrm{dl}$ on her daily postoperative blood counts. No blood products were used at any time.

\section{Discussion}

The use of a blood transfusion is forbidden under JW doctrine. Doctors have no legal right to transfuse someone against their will even if this may result in their death [3]. After extensive discussion at the MDT meeting and with the patient, a comprehensive literature review was undertaken by the operating surgeons. In conjunction with their previous experience of decreased blood loss whilst using the HS it was decided that salvage surgery was the most appropriate course of action.

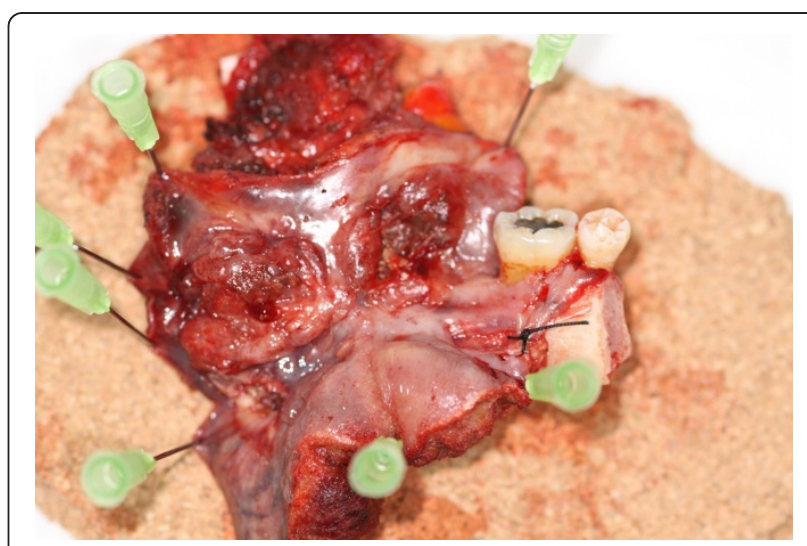

Figure 3 Left tonsillar and retromolar with mandibular rim resection specimen marked with surgical pins to allow orientation by histopathologist. 


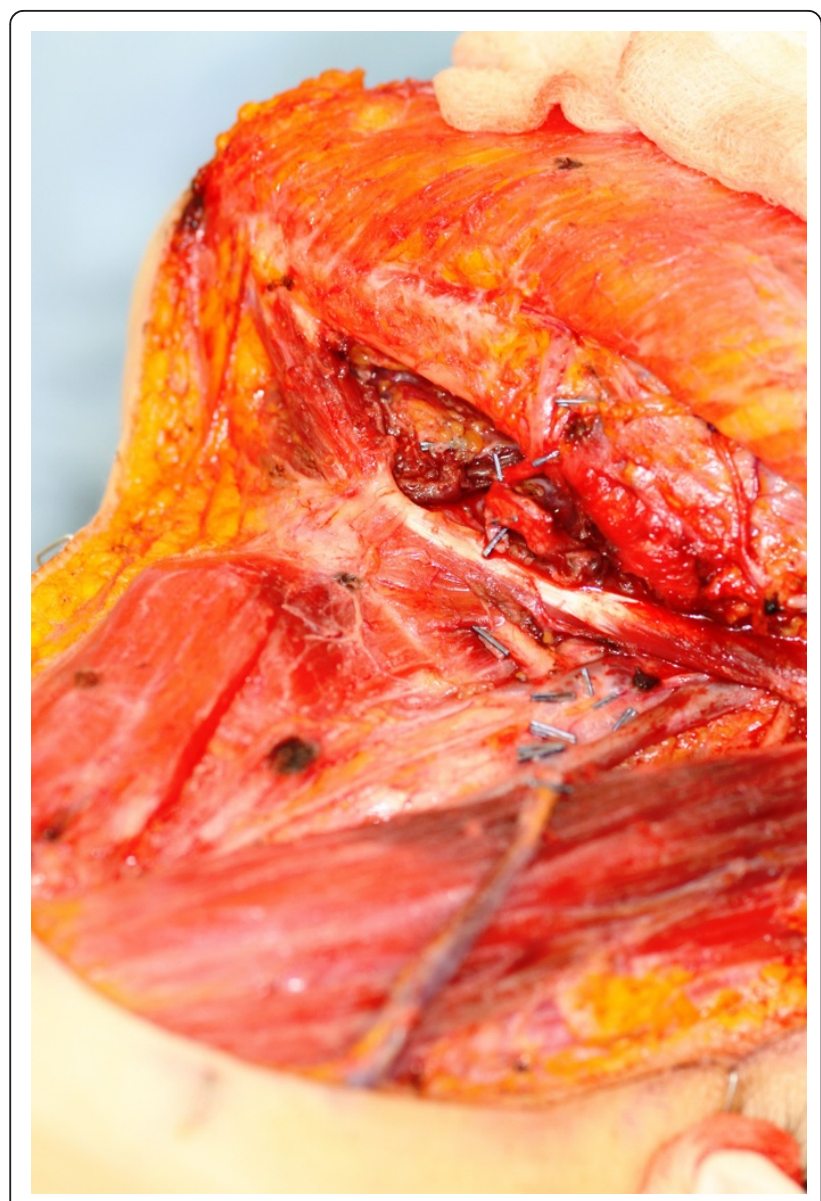

Figure 4 Intra-operative image demonstrating a left level I-IV neck dissection performed with the Harmonic Scalpel.

Blood transfusion, although potentially life-saving is known to be associated with a number of risks. These must be balanced against the potential benefit of transfusion. Reactions range from the self-limiting febrile nonhemolytic transfusion reaction to life threatening conditions such as Transfusion Related Acute Lung Injury (TRALI) [4]. The transmission of blood borne bacteria and viruses (including HIV and hepatitis $\mathrm{B} / \mathrm{C}$ ) also remains a possibility $[5,6]$. Specifically in surgical patients there is a documented link between transfusions and postoperative infections and tumor recurrence [7].

According to the literature, blood transfusion is required in $14-80 \%$ of all head and neck cancer operations [8]. However, within our unit only $16 \%$ of major head and neck operations required blood transfusion (11 of 68 cases transfused between August 2008-August 2009). We have also noted a significant decline in the use of transfusion since we began to use the HS (unpublished data).

In the preoperative and intra-operative periods hypervolameic/normovolemic hemodiltion [9], hypotensive anaesthesia [10] and cell scavenging [11] have all been described to minimize blood loss. Acute normovolemic hemodilution is the process of removing one or more units of blood before the operation for transfusion to the patient either during or at the end of the operation. This was not acceptable to our patient as blood cannot be reused once taken out of circulation. On discussion with our patient cell scavenging was also ruled out as it involves the reinfusion of blood which has left the circulation. We decided on a strategy of hypervolemic hemodilution. Here considerable fluid is administered intravenously to the patient reducing the patient's hematocrit and hence the blood's oxygen carrying capability. This reduces the number of red blood cells lost intraoperatively. The hematocrit is restored with a postoperative diuresis. This strategy is not suitable for patients with cardiovascular or renal dysfunction [9]. We also used controlled hypotension with a mean arterial pressure of $65 \mathrm{mmHg}$ maintained with an opiate infusion. Similarly, the use of controlled hypotension is only recommended in patients known to be free of cardiovascular and respiratory problems [10].

The use of aprotinin and tranxemic acid have also been employed to reduce intra-operative bleeding [12]. Previous surgery in JW have used aprotinin, a bovine derived inhibitor of trypsin and plasmin. However, this was withdrawn in May 2008 due an increased risk of death in cardiac surgical patients [13]. Therefore we followed the recommendation of Henry et al to use the antifibrinolytic agent tranxemic acid. Their meta-analysis showed this to be the most effective antifibinolytic since the withdrawl of aprotinin [12].

There are only a few documented cases of JWs undergoing major head and neck surgery previously presented in the literature. Genden et al present the case of a 35 year old male with a T3NOM0 anterior floor of mouth SCC who successfully underwent a segmented mandibulectomy and staged fibula free flap reconstruction with osseointegrated dental implants without use of allogenic blood [14]. Van Hemelen et al present two JWs with oral cancer requiring neck dissection and free flap transfer without use of blood transfusion [15]. Skoner et al's presentation of $5 \mathrm{JWs}$ with head and neck cancers requiring 7 free flap reconstructions is the largest series in the literature so far [16]. However, our case is the first presentation of the use of the HS in this patient population.

Preoperative planning requires extensive discussion between all parties involved. Particularly, the patient must be aware that refusal of blood products may have life endangering consequences. Our patient was fully optimized before surgery. A full medical and surgical history was taken to identify any risk factors adversely affecting hemostasis. We restricted pre- and post- 
operative phlebotomy to a minimum. Preoperative haemoglobin was optimized by a course of ferrous sulphate. We considered the use of recombinant erythropoientin (EPO), to raise preoperative haemoglobin levels. EPO is a glycosylated polypeptide released by the kidney in response to hypoxia which increases erythropoietic precursors in the bone marrow and has been shown to be a useful in avoiding transfusion in surgical specialties including head and neck $[17,18]$. Remmers et al suggested the use of EPO and iron 2 to 3 weeks before elective surgery in JW [19].

However, the use of EPO has been associated with increased recurrence in head and neck cancer patients [20]. Janecka speculates that this may be due to EPO promoting thrombogenesis and hence tumor hypoxia and angiogenesis [21]. Conversely, a more recent trial failed to shown any negative impact of EPO therapy on patient survival or tumor recurrence [22]. We decided against the use of EPO in this case. The use of recombinant clotting factors and DDAVP was also thought inappropriate in a patient with a physiologically normal clotting profile.

With our unit's experience of the HS and a comprehensive literature review we felt the use of the HS would allow meticulous hemostatis and thus reduce the chances of requiring blood products. The traditional surgical method for head and neck cancer resections is 'cold steel' dissection. Here blood loss is controlled using pressure or ligatures. Monopolar and bipolar electrosurgery are newer methods of dissection which use heat to cauterise bleeding vessels. The HS is a surgical cutting device which concurrently coagulates tissues. The basic principle of this device is converting an ultrasonic wave into high frequency mechanical energy, vibrating the cutting surfaces at $55.5 \mathrm{Khz}$. The cutting blade is able to denature proteins into a coagulum which acts as a haemostatic seal around blood vessels [23]. This allows optimal surgical visibility in a near bloodless operating field [24]. The harmonic scalpel operates at lower temperatures (50-100 C) compared to mono- or bipolar devices (100-600 C) hence there is less tissue damage and the subsequent inflammatory response is also lessened. The lower operating temperatures mean that neighbouring structures are at less risk of damage hence allowing the surgeon to work around delicate structures [25].

There is also less eschar formation and hence less smoke production. Due to the lower temperatures of the harmonic scalpel as compared to conventional thermal surgical instruments less tissue sticks to the blades. This decreases tissue damage and wasted time cleaning and exchanging instruments [26,27].

A number of studies have shown that operative time, blood loss and hospital stay are shortened in a wide range of head and neck such as tonsillectomy [28] and thyroidectomy [25-27], general [29] and gynaecological surgery [30]. Initial results have been favourable with less postoperative pain, lower blood loss, shortened operative time and lack of impairment of histopathologic evaluation.

Salami et al present a non-randomized study comparing 40 pharyngolarygectomy, 40 total laryngectomy, 40 unilateral neck dissections and 40 superficial parotidectomies with either the harmonic scalpel or 'cold steel' dissection [31]. The evaluation demonstrated a significant decrease in operative time, intra-operative blood loss, total hospital stay, postoperative seroma formation and subjective pain scores for patients treated with the HS.

\section{Conclusions}

In summary, JW present a major challenge to the head and neck cancer surgeon. We believe preoperative optimisation with ferrous sulphate, the use of hypervolameic hemodilution with the addition of tranexamic acid and meticulous attention to intra-operative hemostasis with the HS are the cornerstones of management for these patients. We found the use of the HS in conjunction with our anaesthetic techniques created an almost bloodless operating field and enabled a large cancer resection and reconstruction to be performed without recourse to blood transfusion. We feel the HS will play an important role in bloodless surgery in the future.

\section{Consent}

Written informed consent was obtained from the patient's next of kin for publication of this case report and accompanying images. A copy of the written consent is available for review by the Editor-in-Chief of this journal.

\section{Author details}

'Department of Maxillofacial Surgery Royal Victoria Hospital Newcastle-UponTyne UK. ${ }^{2}$ Department of Plastic Surgery Royal Victoria Hospital NewcastleUpon-Tyne UK.

\section{Authors' contributions}

PK and KS prepared the manuscript. JA was lead surgeon and reviewed the manuscript. All authors read and approved the final version.

Competing interests

The authors declare that they have no competing interests.

Received: 31 January 2011 Accepted: 3 October 2011

Published: 3 October 2011

\section{References}

1. Watchtower: What is God's Law on blood? 2011, [cited 2011 2011]; Available from: http://www.watchtower.org/.

2. Mclnroy A: Blood transfusion and Jehovah's Witnesses: the legal and ethical issues. Br J Nurs 2005, 14(5):270-4.

3. Goff L: Re F (Mental Patient: Sterilisation). 1990 
4. Williamson LM, et al: Serious hazards of transfusion (SHOT) initiative: analysis of the first two annual reports. BMJ 1999, 319(7201):16-9.

5. Regan F, Taylor C: Blood transfusion medicine. BMJ 2002, 325(7356):143-7.

6. Stainsby $\mathrm{D}$, et al: Reducing adverse events in blood transfusion. $\mathrm{Br} J$ Haematol 2005, 131(1):8-12.

7. Amato A, Pescatori M: Reported noncausal effect of blood transfusions on colorectal cancer recurrence. Ann Surg 1997, 225(1):129-30.

8. Krupp NL, et al: Validation of a transfusion prediction model in head and neck cancer surgery. Arch Otolaryngol Head Neck Surg 2003, 129(12):1297-302.

9. Kreimeier U, Messmer K: Hemodilution in clinical surgery: state of the art 1996. World J Surg 1996, 20(9):1208-17.

10. Hack H, Mitchell V: Hypotensive anaesthesia. Br J Hosp Med 1996, 55(8):482-5

11. Nieder AM, et al: Intraoperative cell salvage during radical prostatectomy is not associated with greater biochemical recurrence rate. Urology 2005, 65(4):730-4.

12. Henry DA, et al: Anti-fibrinolytic use for minimising perioperative allogeneic blood transfusion. Cochrane Database Syst Rev 2001, , 1: CD001886.

13. FDA Drug Information: Information for Healthcare Professionals: Aprotinin (marketed as Trasylol). 2007, Available from: http://www.fda.gov/Drugs/ DrugSafety/PostmarketDrugSafetyInformationforPatientsandProviders/ ucm142720.htm.

14. Genden EM, Haughey BH: Head and neck surgery in the Jehovah's Witness patient. Otolaryngol Head Neck Surg 1996, 114(4):669-72.

15. Van Hemelen $G$, et al: Management of Jehovah's Witness patients undergoing major head and neck surgery. Head Neck 1999, 21(1):80-4.

16. Skoner JM, Wax MK: Microvascular free-tissue transfer for head and neck reconstruction in Jehovah's Witness patients. Head Neck 2008, 30(4):455-60

17. Atabek $U$, et al: Erythropoetin accelerates hematocrit recovery in postsurgical anemia. Am Surg 1995, 61(1):74-7.

18. Sturgis EM, et al: Avoiding transfusion in head and neck surgery: feasibility study of erythropoietin. Laryngoscope 2000, 110(1):51-7.

19. Remmers PA, Speer AJ: Clinical strategies in the medical care of Jehovah's Witnesses. Am J Med 2006, 119(12):1013-8.

20. Henke $M$, et al: Erythropoietin to treat head and neck cancer patients with anaemia undergoing radiotherapy: randomised, double-blind, placebo-controlled trial. Lancet 2003, 362(9392):1255-60.

21. Janecka IP: Erythropoietin to treat anaemia in patients with head and neck cancer. Lancet 2004, 363(9413):993-4.

22. Hoskin PJ, et al: Effect of epoetin alfa on survival and cancer treatmentrelated anemia and fatigue in patients receiving radical radiotherapy with curative intent for head and neck cancer. J Clin Oncol 2009, 27(34):5751-6.

23. Ethicon: Harmonic technology 2011, Available from: http://www. ethiconendosurgery.com/Clinician/Product/energy.

24. Carroll T, Ladner K, Meyers AD: Alternative surgical dissection techniques. Otolaryngol Clin North Am 2005, 38(2):397-411.

25. Siperstein $A E$, Berber $E$, Morkoyun $E$ : The use of the harmonic scalpel vs conventional knot tying for vessel ligation in thyroid surgery. Arch Surg 2002, 137(2):137-42.

26. Ortega J, et al: Efficacy and cost-effectiveness of the UltraCision harmonic scalpel in thyroid surgery: an analysis of 200 cases in a randomized trial. J Laparoendosc Adv Surg Tech A 2004, 14(1):9-12.

27. Papavramidis TS, et al: UltraCision harmonic scalpel versus clamp-and-tie total thyroidectomy: a clinical trial. Head Neck 2010, 32(6):723-7.

28. Neumann C, et al: Harmonic scalpel tonsillectomy: a systematic review of evidence for postoperative hemorrhage. Otolaryngol Head Neck Surg 2007, 137(3):378-84.

29. Gelmini R, et al: Laparoscopic cholecystectomy with Harmonic scalpel. JSLS 2010, 14(1):14-9.

30. Kunde $D$, Welch C: Ultracision in gynaecological laparoscopic surgery. J Obstet Gynaecol 2003, 23(4):347-52.

31. Salami $A$, et al: New trends in head and neck surgery: a prospective evaluation of the Harmonic Scalpel. Med Sci Monit 2008, 14(5):PI1-5.

doi:10.1186/1477-7819-9-115

Cite this article as: Kullar et al:: Case report: The management of advanced oral cancer in a Jehovah's Witness using the Ultracision Harmonic Scalpel. World Journal of Surgical Oncology 2011 9:115.

\section{Submit your next manuscript to BioMed Central and take full advantage of:}

- Convenient online submission

- Thorough peer review

- No space constraints or color figure charges

- Immediate publication on acceptance

- Inclusion in PubMed, CAS, Scopus and Google Scholar

- Research which is freely available for redistribution

Submit your manuscript at www.biomedcentral.com/submit
Biomed Central 